\title{
Balloon-assisted endoscopic sclerotherapy: a novel technology
}

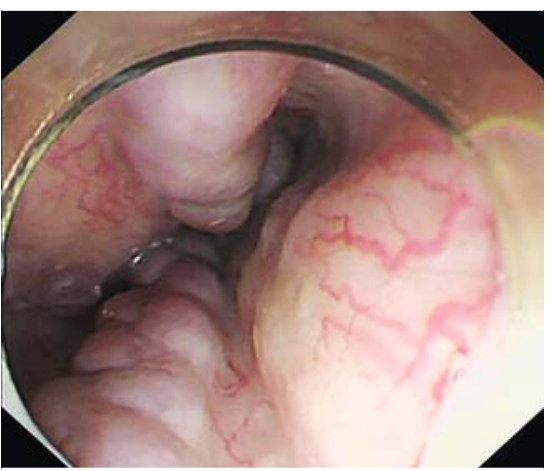

- Fig. 1 Endoscopy revealed the presence of four varices in the esophagus, with a maximum diameter of $1.0 \mathrm{~cm}$.

Endoscopic injection sclerotherapy is an effective method for treating esophageal variceal hemorrhage [1, 2]. However, owing to the rapid loss of the sclerosing agent, the overall effect of sclerotherapy is weakened. Therefore, increasing the residence time of the sclerosing agent remains a focal point of current investigations. The present study reported a case treated with a novel technology termed balloon-assisted endoscopic sclerotherapy.

A 48-year-old man was admitted to our department following a diagnosis of esophageal varices. An endoscopy revealed the presence of four varices in the esophagus, with a maximum diameter of $1.0 \mathrm{~cm}$ ( $\triangleright$ Fig. 1). Therefore, endoscopic balloon-assisted sclerotherapy was immediately performed. The balloon was inserted on the front end of the gastroscope and fixed at a distance of 3 to $5 \mathrm{~cm}$ from the tip ( $>$ Fig. 2 ). The inner diameter of the balloon was $1.1 \mathrm{~cm}$, and the outer diameter before and after inflation was $1.3 \mathrm{~cm}$ and $1.8 \mathrm{~cm}$, respectively. The endoscope was then used to enter the vicinity of the treated blood vessel, and the balloon was opened up and inflated with $2 \mathrm{ml}$ of air ( $>$ Fig. 3). Following this procedure, the selected blood vessel was subsequently treated with sclerotherapy.

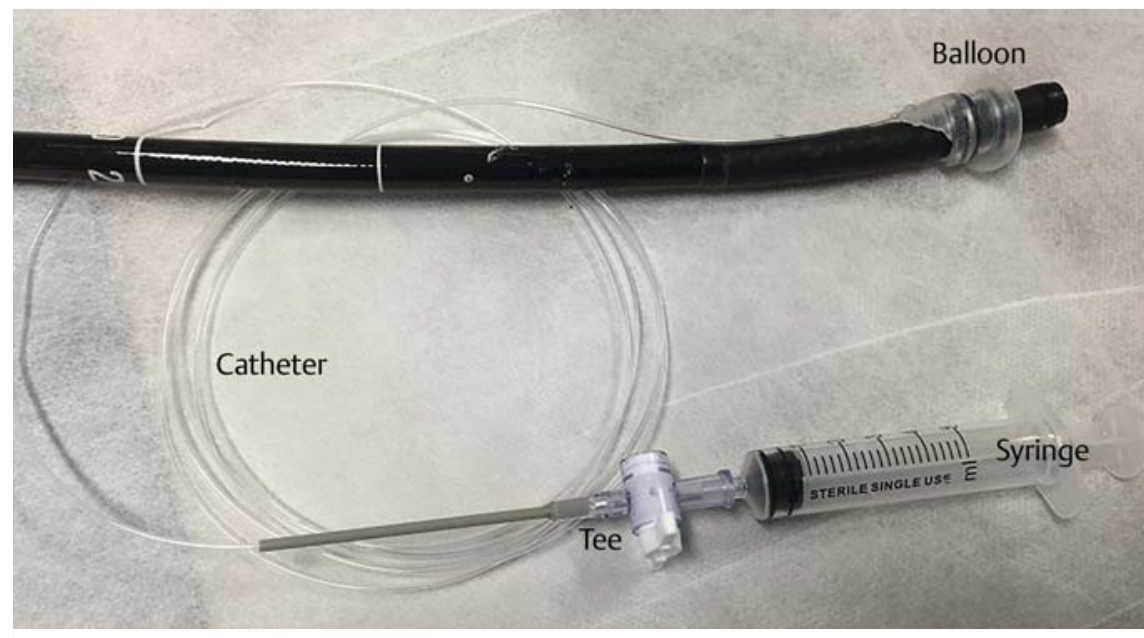

- Fig. 2 Components of the device include the balloon, catheter, and tee. The balloon was inserted from the front end of the gastroscope and fixed at a distance of 3 to $5 \mathrm{~cm}$ from the tip.

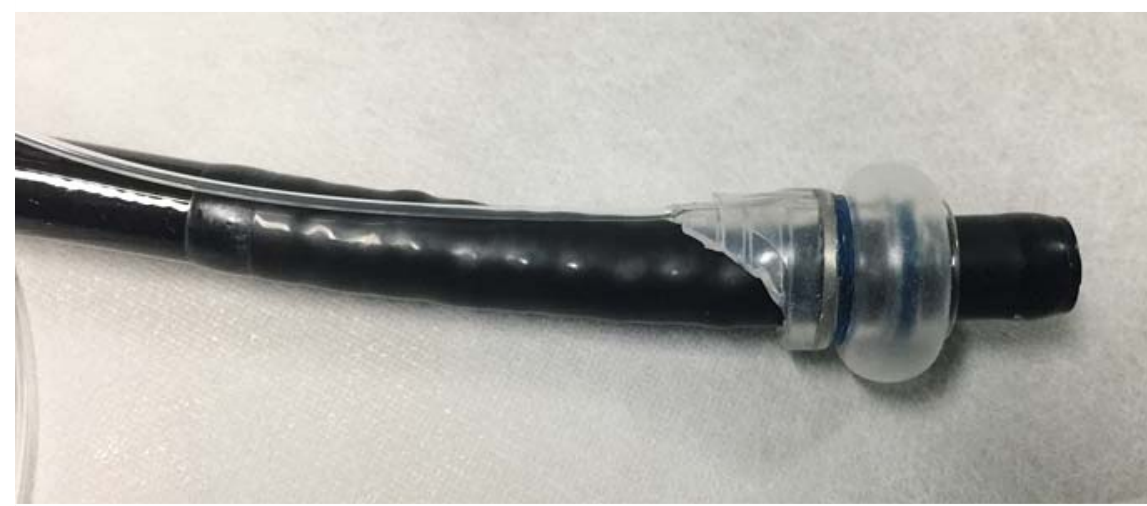

- Fig. 3 The balloon was filled with $2 \mathrm{ml}$ of air.

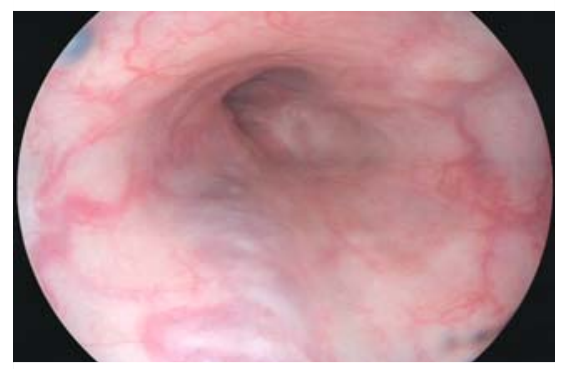

- Fig. 4 On follow-up 1 month later, the patient's varicose veins were significantly atrophied.

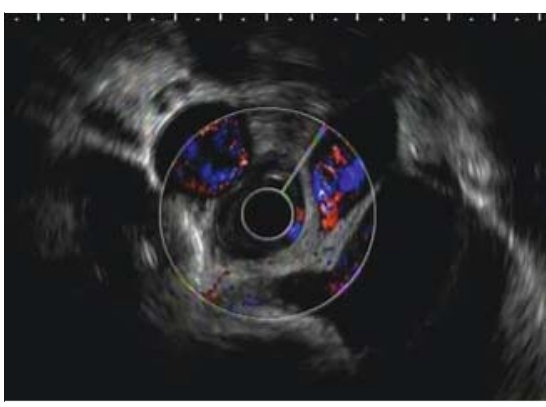

- Fig. 5 Endoscopic ultrasonography showed no obvious blood flow signal under the varicose vein. 


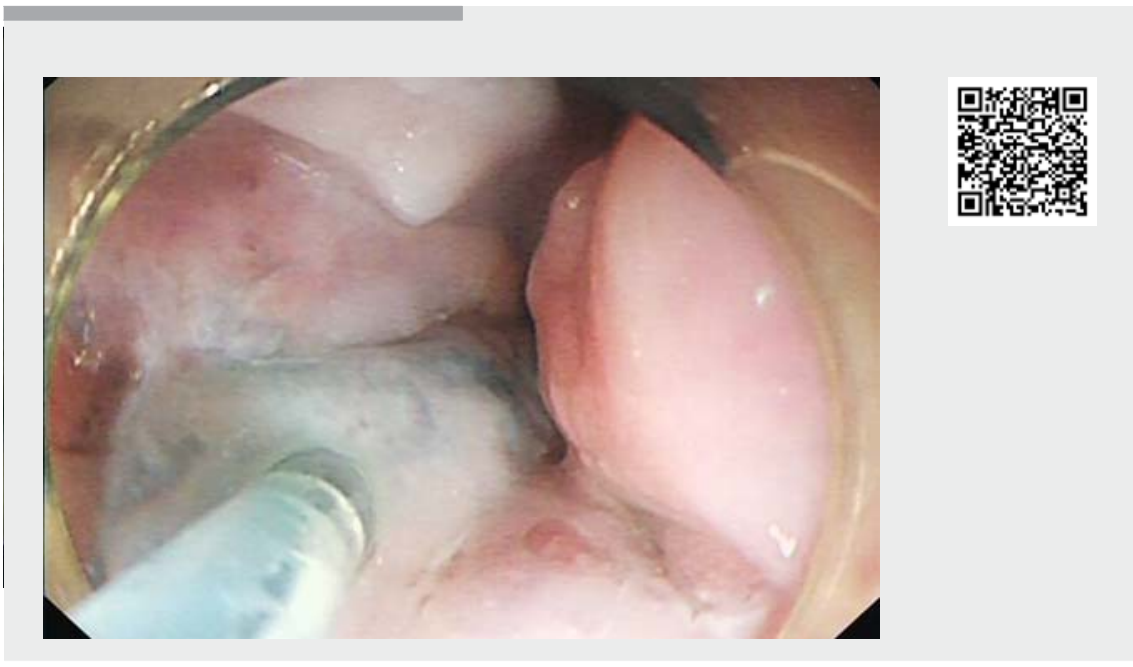

Video 1 A case treated with a novel technology termed balloon-assisted endoscopic sclerotherapy.

Briefly, the sclerosing agent $(10 \mathrm{ml}$ polycinnamyl alcohol $+0.1 \mathrm{ml}$ meilan) was injected into the blood vessel and the balloon was used to continuously compress the blood vessel for 10 minutes ( $\bullet$ Video 1). The tee was closed after the air in the balloon was completely deflated. On follow-up 1 month later, the patient's varicose veins were significantly atrophied ( Fig.4), and endoscopic ultrasonography showed no obvious blood flow signal under the varicose vein ( $\bullet$ Fig. 5 ).

In conclusion, balloon-assisted sclerotherapy under endoscopy was discovered to improve the therapeutic efficacy of the sclerosing agent. Compared with Tatsuyuki Kawano's balloon method [3], the present method was also simpler and more practical.

Endoscopy_UCTN_Code_TTT_1AO_2AD

Competing interests

The authors declare that they have no conflict of interest.

\section{References}

[1] Ali SM, Wu S, Xu H et al. A prospective study of endoscopic injection sclerotherapy and endoscopic variceal ligation in the treatment of esophageal varices. J Laparoendosc Adv Surg Tech A 2017; 27: 333-341

[2] Kumar S, Asrani SK, Kamath PS. Epidemiology, diagnosis and early patient management of esophagogastric hemorrhage. Gastroenterol Clin North Am 2014; 43: 765-782

[3] Kawano T, Nakamura H, Inoue $\mathrm{H}$ et al. Endoscopic injection sclerotherapy using a transparent overtube with intraluminal negative pressure (np-EIS) for esophageal varices. Surg Endosc 1990; 4: 15-17

\section{Bibliography}

Endoscopy 2021; 53: E343-E344

DOI 10.1055/a-1290-7001

ISSN 0013-726X

published online 11.11 .2020

(c) 2020. Thieme. All rights reserved.

Georg Thieme Verlag KG, Rüdigerstraße 14,

70469 Stuttgart, Germany

Xuecan Mei ${ }^{1{ }^{*}}$, Xi Wang ${ }^{1,{ }^{*}}$, Wenyue Wu ${ }^{1}$, Yi Xiang', Yi Han², Derun Kong',2

1 Department of Gastroenterology, the First Affiliated Hospital of Anhui Medical University, Hefei, Anhui, China

2 Department of Gastroenterology, Fuyang Hospital of Anhui Medical University, Fuyang, Anhui, China

\section{Corresponding author}

\section{Derun Kong, MD}

Department of Gastroenterology, First Affiliated Hospital of Anhui Medical University, 218 Jixi Road, Shushan District, Hefei 230022, Anhui Province, China Fax: +86-551-63633742

kongderun168@163.com

\section{ENDOSCOPY E-VIDEOS}

https://eref.thieme.de/e-videos

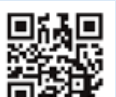

Endoscopy E-Videos is a free access online section, reporting on interesting cases and new techniques in gastroenterological endoscopy. All papers include a high quality video and all contributions are freely accessible online.

This section has its own submission website at https://mc.manuscriptcentral.com/e-videos

* Joint first authors 